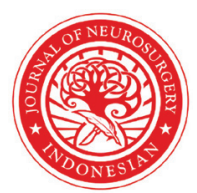

Indonesian Journal of Neurosurgery

\section{Non-powder lateral penetrating craniocerebral gunshot wound in a 10-year-old girl: A case report}

\author{
Donny Argie', Christopher Lauren ${ }^{1 *}$, Elric Brahm Malelak'
}

CrossMark
'Department of Neurosurgery, Prof. Dr. W. Z. Johannes Kupang Regional General Hospital, Kupang, East Nusa Tenggara, Indonesia;

\section{*Corresponding author:}

Christopher Lauren;

Department of Neurosurgery, Prof. Dr. W. Z. Johannes Kupang Regional General Hospital, Kupang, East Nusa Tenggara, Indonesia;

chrislauren11@gmail.com

Received: 2021-06-08

Accepted: 2021-10-23

Published: 2021-12-03

\section{ABSTRACT}

Introduction: Non-powder lateral penetrating craniocerebral gunshot wounds (PCGW) is one of the lethal types of penetrating head injury. The mortality rate is higher in adults than in pediatric populations and influenced by the clinical and radiologic findings as to the important predictors for prognostication in patients with PGCW.

Case presentation: A 10-year-old girl presented with a gunshot wound to the head 1 day prior. She was accidentally shot by her brother with an air gun from approximately 2 feet from the gun barrel. She develops a loss of consciousness for 30 minutes and weakness over the left arm. On physical examination, the Glasgow Coma Scale (GCS) was E3V5M6, weakness on the left arm, and an entrance wound over the right temple without an exit wound. The skull X-ray showed the pellet fragment and the computed tomography (CT) scan showed the bullet track starting from the right frontotemporal towards the left parietooccipital region, damaging both hemispheres with associated intraventricular hemorrhage (IVH). She was undergone a craniotomy procedure to remove the bullet fragment, debridement of the necrotic tissue, and evacuate the blood clot over the bullet track. The patient was discharged after postoperative day 7 with good recovery of neurological function and good GCS and Glasgow Outcome Scale (GOS) score. After 6 months of follow-up, neither a new deficit nor other signs and symptoms were developed.

Conclusion: Non-powder PCGW can cause significant damage to the intracranial compartment, despite its low velocity. The mortality rate in pediatrics is lower than in the adult population. The management mandated an urgent surgical procedure to remove any blood clot and debridement of any foreign bodies encountered. Such complications in the short- or long term can be developed in any patient and should be treated expectantly.

Keywords: guns, neurosurgery, non-powder firearms, pediatric, traumatic brain injury.

Cite This Article: Argie, D., Lauren, C., Malelak, E.B. 2021. Non-powder lateral penetrating craniocerebral gunshot wound in a 10-year-old girl: A case report. Indonesian Journal of Neurosurgery 4(3): 98-102. DOl: 10.15562/ijn.v4i3.152

\section{INTRODUCTION}

Non-powder lateral penetrating craniocerebral gunshot wounds (PCGW) are one of the lethal types of penetrating intracranial injury. Non-powder or air gun is the type of weapon that used carbon dioxide or compressed air to form energy to shoot a ball bearing (BB) or pellet type bullet. ${ }^{1}$ This type of injury is mostly found in patients aged under 19-year-old who played with an air gun as a toy without parental supervision. ${ }^{2-4}$ The mortality rate is higher in adults than in pediatric populations and influenced by the clinical and radiologic findings as the important predictors for prognostication in patients with PCGW. ${ }^{5}$ The lateral type of PCGW, unlike the anteroposterior (AP) PCGW, also increase the mortality rate significantly in all patients. ${ }^{6}$ However despite its lower mortality in the pediatric population, the short-or long terms complication such as infection, seizures, hydrocephalus, and impairment of neurobehavioral development still can occur in all ages..$^{7-10}$

Here, we presented a case report about a 10-year-old girl that suffered from a non-powder lateral PCGW treated in our facilities. We provided a detailed description of the clinical course, physical examination, supportive examination such as plain skull X-ray and computed tomography (CT) scan findings, management, follow-up findings, and review of this case based on previously reported studies and literature.

\section{CASE PRESENTATION}

\section{History}

A 10-year-old girl was brought by her parents to the emergency department because of a gunshot wound to the head 1 day prior. She was accidentally shot by her brother with an air gun when they were playing around from approximately 2 feet from the gun barrel. After the injury, she developed a loss of consciousness for approximately 30 minutes and was brought to the peripheral hospital emergency unit 1 hour later. Because there were no facilities such as CT scan examination and neurosurgical services, she was referred to our facilities 1 day after. Since the admission, she only presented with a primary complaint of weakness over the left arm and pain on the entrance wound. 
There were no other symptoms such as an abnormal sensation, seizure, vomiting, or visual disturbances.

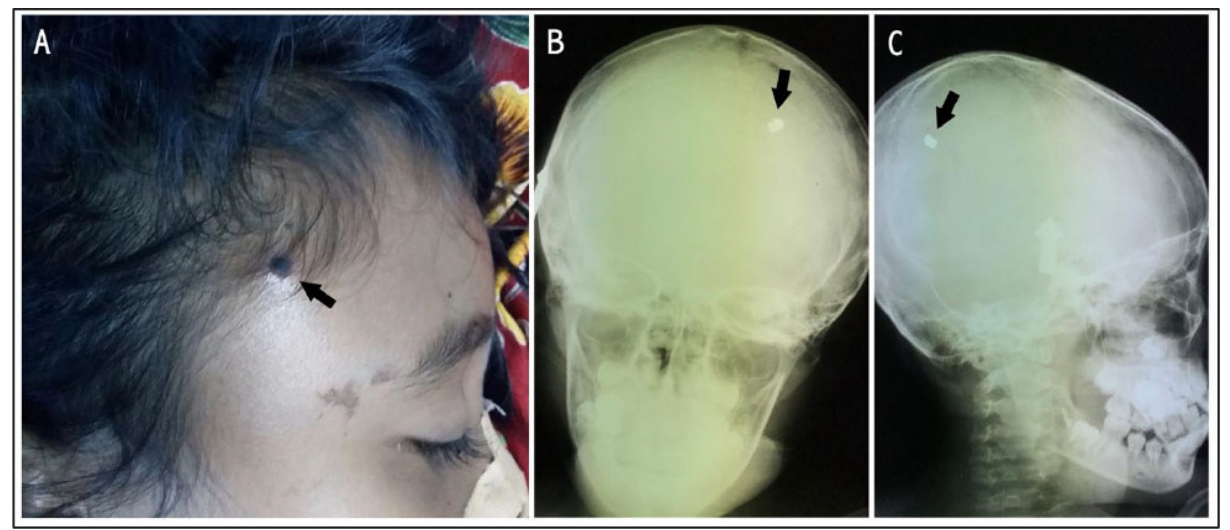

Figure 1. A. The entrance wound is located at the right temple (black arrow). B. Plain skull X-ray in anteroposterior view and C. Lateral view. Both show homogenous dense opacities of the pellet fragment (black arrow).
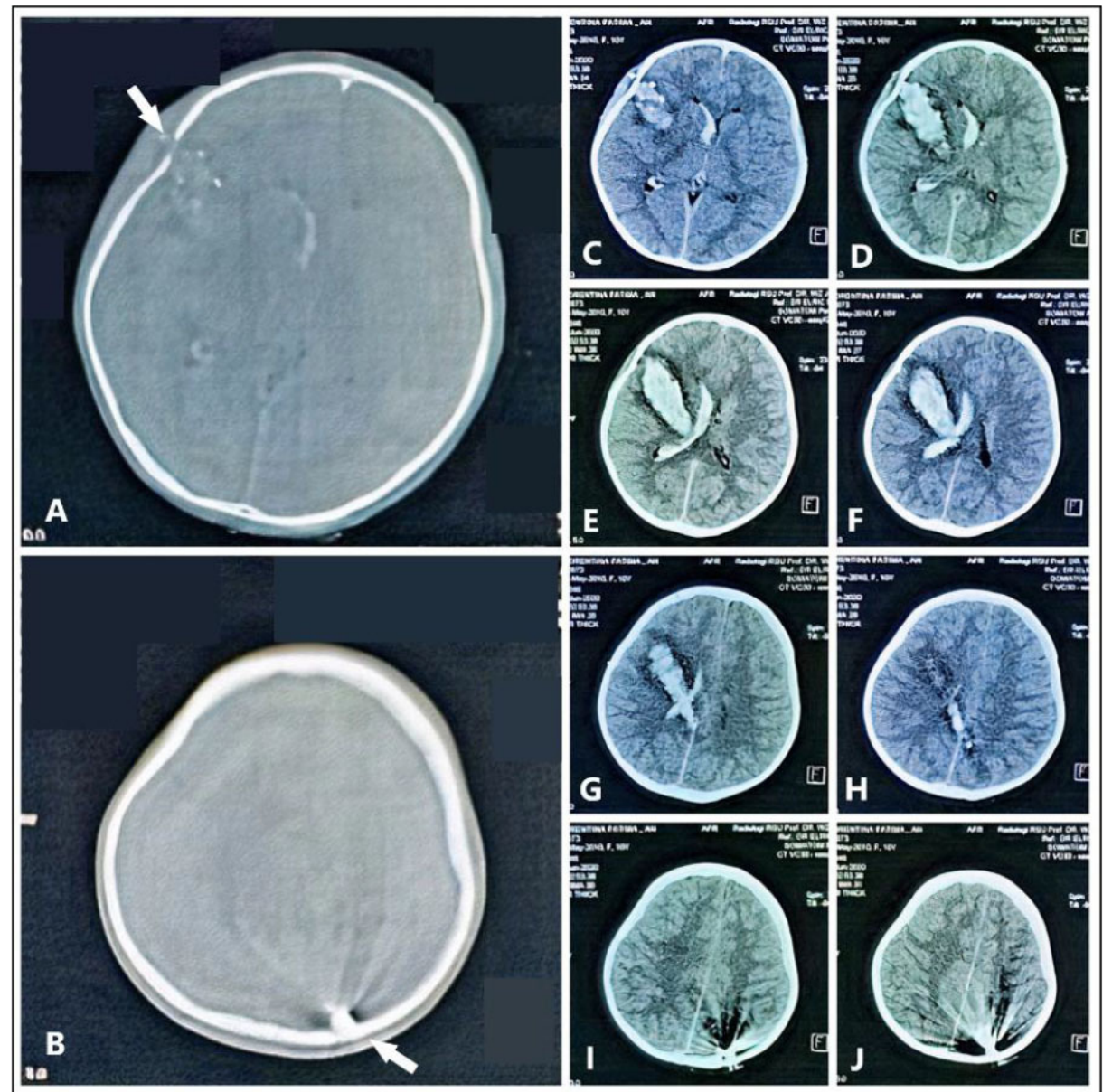

Figure 2. Non-contrast head CT scans in axial view. A. Bone window, showing a fracture of the right frontal bone (white arrow). B. Bone window, the pellet fragment lies on the left side of the parietooccipital region (white arrow). C-J. Soft tissue window, showing the bullet track crossing both hemispheres with associated perifocal edema, hematoma, and IVH. with the Glasgow Coma Scale (GCS) was E3V5M6, both pupils were reactive and $3 \mathrm{~mm}$ in size, and there was lateralization of the left upper extremity with a muscle strength score was 3 . The entrance wound was located over the right temple with a size of approximately 0.7 centimeters $(\mathrm{cm})$ in diameter and no active bleeding over the wound site (Fig. 1A). There was no exit wound and injury found on other extracranial compartments.

A supportive examination such as plain skull X-ray and non-contrast head Computed Tomography (CT) scan were performed. The plain skull $\mathrm{X}$-ray in AP (Fig. 1B) and a lateral view (Fig. 1C) showed the pellet fragment as homogenous dense opacities over the posterior and left side of the skull. The non-contrast head CT scan in the bone window showed a fracture of the right frontal bone with the pellet fragments were lied on the left side of the parietooccipital region without penetrating the overlying bone (Fig. 2A and Fig. 2B). The non-contrast head CT scan in soft tissue window showed the bullet track starting from the right frontotemporal towards the left parietooccipital region, crossing both hemispheres, damaging the brain tissue with associated perifocal edema, hematoma along the track which extend into the right ventricle, causing an intraventricular hemorrhage (IVH) (Fig. 2C-2J). We did not perform a cerebral angiography to look for any injured vessels because there were no such facilities in East Nusa Tenggara.

Based on the complete history taking, physical, and supportive examination, the patient was considered to take a surgical procedure which consisted of removal of the bullet fragment, debridement of the necrotic tissue, and evacuating blood clots over the bullet track.

\section{Operative procedure}

The surgical procedure consisted of craniotomy and debridement procedures which were started with the opening of the left parietooccipital bone. Immediately after opening the bone, the pellet fragment was encountered and had a size of approximately $0.6 \mathrm{~cm}$ in length (Fig. 3). The pellet fragment was penetrating the dura and lied on the 


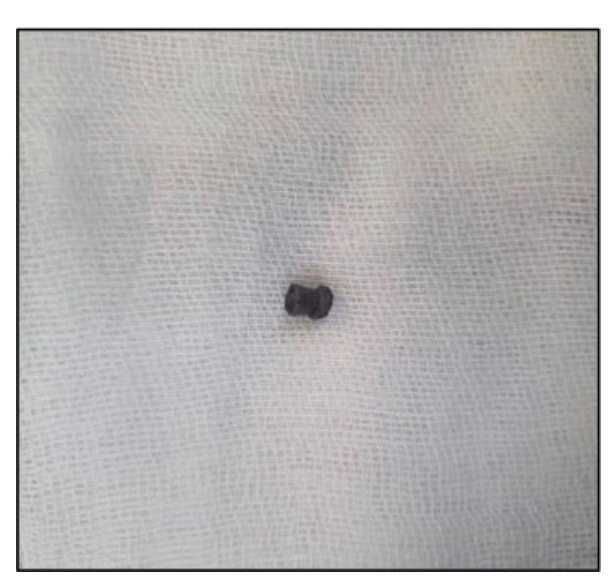

Figure 3. The pellet fragment with a size approximately $0.6 \mathrm{~cm}$ in length.

adjacent bone without damaging it. No brain edema and active bleeding were found on the operative side. The blood clots that were formed over the bullet track were evacuated as much as we can. We performed debridement of the necrotic brain tissue, bone fragment, bullet track, other foreign bodies encountered during operation, and then washed the wound site with a normal saline and hydrogen peroxide. The necrotic brain tissue was removed using a bipolar and suction until healthy brain tissue was encountered. We kept working within the bullet track to avoid injuring the healthy tissue. The dura was closed with a synthetic dura with a watertight closure technique and fibrin glue. We closed the craniotomy side with a bone flap and sequentially sutured the overlying scalp. This procedure lasted for about 2 hours.

\section{Postoperative management}

After the surgical procedure, the patient was given intravenous (IV) empiric antibiotics to cover positive and negative gram organisms such as ceftriaxone and metronidazole, seizure prophylactic such as IV phenytoin, osmotic diuretic such as mannitol, and positioning of the patient head in $30^{\circ}-45^{\circ}$ degrees. The patient was hospitalized until postoperative day 7 with an improved motoric function which was shown by an increased muscle strength score from 3 to 4. GCS score was E4V5M6, Glasgow Outcome Scale (GOS) score was 5 , and no other neurological deficit nor seizures was found during in-hospital observation. On follow-up, we found neither a new neurological deficit nor other signs and symptoms were developed.

\section{DISCUSSION}

PCGW is the most fatal type of ballistic injury to the head. ${ }^{5,11}$ The mortality rate for PCGW in the adult and the pediatric population is nearly $90 \%$ and $65 \%$, respectively. ${ }^{5,12}$ Based on the data from the Centers for Disease Control and Prevention (CDC) from 2004-2010, the reported cases of PCGW in the adult population are 6.34 death in 100.000 population and the pediatric population is 1.42 death in 100.000 population. ${ }^{5}$

Non-powder weapons or airguns are types of weapons that use energy from carbon dioxide or air compression to shoot a BB or pellet-type bullet. ${ }^{1}$ Nearly $80-90$ $\%$ of patient who suffers from PCGW are male gender aged under 19-year-old and commonly caused by misuse of the weapon without parental supervision..$^{2-4}$ It is categorized as low-velocity missiles, which have a muzzle velocity $<300 \mathrm{~m} / \mathrm{s}$. Despite its low velocity, this type of weapon can generate a high impact of damage because it only needs a velocity of nearly as $60-100 \mathrm{~m} / \mathrm{s}$ to break and penetrate the skull. ${ }^{13-15}$ Based on reported cases by O'Neill et al., a total of three patients who suffer from intracranial injuries caused by non-powder gunshot wounds, two patients died despite aggressive treatment which shows that this type of injury has a high mortality rate. ${ }^{1}$

The bullet trajectory from the axial plane has a different rate of mortality based on the bullet direction when penetrating the head. It is divided into two main types, the AP PCGW and lateral PCGW which have a mortality rate of $25 \%$ and $83 \%$, respectively. The lateral PCGW is the most lethal type of intracranial penetration, which show in our reported case. ${ }^{6}$ Unfortunately, despite the high mortality rate of this type of injury from the previous study, this patient has a good clinical condition, excellent GCS and GOS score at discharge, and 1 year of follow-up.

Admission GCS also affects the prognostication of a patient with PCGW. Several studies concluded that GCS $\leq 5$ commonly produced a high mortality rate, nearly $95 \% .^{8,16,17}$ Besides the admission GCS, another predictor for prognostication is the initial head CT scan. There are several predictors, which are the presence of intraventricular hemorrhage, the involvement of more than 1 lobes, and bihemispheric injury. ${ }^{18}$ The presence of intraventricular hemorrhage is one of the most important predictors that cause a high morbidity and mortality rate in PCGW. ${ }^{19,20}$ The involvement of more than one lobes also affects the prognosis, which is reported by several studies that involvement of only 1 lobe causes a mortality rate of $54.2 \%$, while the involvement of $\geq 2$ lobes causing a quite significant difference which is $88.9 \% .{ }^{17}$ The prognosis worsens if there is a bihemispheric involvement, who makes the survival rate decrease to only $15-17$ $\% .{ }^{8,16}$ Although the patient in our case has all the components mentioned above in the initial head CT scan, unfortunately, in fact, the patient presented an excellent GCS and GOS score at discharge and oneyear follow-up. This is also similar to a study by Coughlan et al., whose mortality in a pediatric patient with PCGW is lower than an adult. ${ }^{21}$

Nowadays, there is already an available scoring system to prognosticate pediatric patients with PCGW. The St. Louis score is one of the scoring systems, which can be used early in the emergency unit to predict the patient's prognostication despite any given therapy. ${ }^{5,22}$ This scoring system has a maximum score of 18 points using clinical and radiographic evidence of the patient. The sensitivity and specificity of this scoring system are $94.13 \%$ and $75.68 \%$, respectively. A score $\geq 5$ predicts a worse prognosis of a patient with PCGW, while a score $\leq 4$ predicts a higher survival rate. The positive predictive value (PPV) to predict death is $78.05 \%$ and the negative predictive value (NPV) for survival is $93.3 \% .^{5}$ In this case, the patient score is 3 because of the involvement of at least 3 lobes and bihemispheric injury. This patient has a higher survival rate based on the St. Louis score.

Management of PCGW in pediatric patients usually consists of urgent surgical treatment, which can significantly affect the long-term clinical improvement of the patient. ${ }^{23}$ The surgical procedure consists of 4 stages, which are immediate lifesaving, 
preventing an acute and chronic infection, protecting the viable brain tissue, and repairing the head anatomic structure. ${ }^{6,24}$ In this case, the surgical procedure consists of craniotomy to remove the blood clot, pellet fragment, control any active bleeding, and debridement of the necrotic brain tissue, displaced bone fragment, or any foreign object identified during surgery.

There is no intracranial pressure (ICP) monitoring in our facilities. Therefore to predict any increase of ICP, we monitored the vital signs, search for any component present in the Cushing triad, or any worsening of presenting neurological deficit or development of new deficit in the patient. The management of increased ICP in our facilities consist of mannitol or hypertonic saline infusion, hyperventilation, head up for $30^{\circ}$, and installation of an endotracheal tube with muscle relaxant, sedative, and positive pressure ventilation especially for GCS $\leq$ $8 .^{25}$

A common complication that may appear even in short or long-term followup is an infection, hydrocephalus, seizures, and impairment of neurobehavioral development. As a neurosurgeon in developing countries, we have several management that we could do in our facilities. Patients with an infection complicated from PCGW can present either with meningitis, epidural abscess, subdural empyema, or brain abscess. ${ }^{8}$ Any management must be adapted according to the cause which consists of antibiotic drug regiment, surgical management to drain any pus, and excised any abscess that develops. In hydrocephalus, especially for the communicating type necessitate placement of a cerebrospinal fluid (CSF) diversion device such as a ventriculoperitoneal shunt to help drain the impaired CSF drainage. ${ }^{9}$ The development of seizures dictates aggressive management because can worsen the patient's condition. ${ }^{10}$ For a patient who presents with seizures, especially those who develop $>7$ days after the insult, we performed a second head CT scan to search for any retained foreign body inside the wound such as bone or pellet fragment. The management consists of anticonvulsant medication and debridement for any retained foreign body that is found on the second CT scan or other procedure to manage any presenting cause that will provoke the seizures. The PCGW also impaired neurobehavioral development, especially in pediatric patients. A study by Ewingcobbs et al. reported that patients aged 5 - 14-year old that suffer from PCGW will produce a disability that is associated with impairment to concentrate, ability to adapt, and behavioral disturbances. This study also showed that patients with PCGW will produce a more significant impairment of neurobehavioral development compared to a patient who suffers from severe closed head injuries in the same ages.?

\section{CONCLUSION}

PCGW is one of the most lethal types of penetrating head injuries. Non-powder or air gun PCGW are more commonly found in pediatric patients and cause a variety of damage to the intracranial compartment. The management mandated an urgent surgical procedure such as craniotomy to remove any blood clot and debridement of bone fragment, bullet fragment, or any foreign bodies encountered. Complications such as infection, hydrocephalus, seizures, and cognitive impairment cannot be avoided and should be treated expectantly. The outcome of the pediatric patient is better than adults, as reported by previous studies and in this case, the patient only presented a mild neurological function with a good GCS and GOS at discharge and 1-year followup. Children need to be supervised by parents when playing around with an air gun, because although it is a toy, still it can cause significant damage as presented in our case.

\section{FUNDING}

There is no funding are used in this study.

\section{CONFLICT OF INTEREST}

There are no conflicts of interest.

\section{AUTHOR CONTRIBUTIONS}

Christopher Lauren contributed to concepts, design, literature search, manuscript preparation, manuscript editing, and manuscript review. Donny Argie contributed to concepts, design, manuscript preparation, manuscript review, and guarantor. Elric Brahm Malelak contributed to concepts, design, manuscript preparation, manuscript review, and guarantor.

\section{REFERENCES}

1. O’Neill PJ, Lumpkin MF, Clapp B, Kopelman TR, Matthews MR, Cox JC, et al. Significant pediatric morbidity and mortality from intracranial ballistic injuries caused by nonpowder gunshot wounds. Pediatr Neurosurg. 2009; 45(3): 205 - 9. https://doi. org/10.1159/000222671.

2. Wijaya AT, Ayusta IMD, Niryana IW. Air gun wound: Bihemispheric penetrating brain injury in a paediatric patient. BJR Case Rep. 2018; 5(2): 20180070. https://doi.org/10.1259/ bjrcr.20180070.

3. McQuirter JL, Rothenberg SJ, Dinkins GA, Norris K, Kondrashov V, Manalo M, Todd AC. Elevated blood lead resulting from maxillofacial gunshot injuries with lead ingestion. J Oral Maxillofac Surg. 2003; 61(5): 593 - 603. https:// doi.org/10.1053/joms.2003.50117.

4. Martínez-Lage JF, Mesones J, Gilabert A. Airgun pellet injuries to the head and neck in children. Pediatr Surg Int. 2001; 17(8): 657 - 60. https://doi.org/10.1007/s003830100018.

5. DeCuypere M, Muhlbauer MS, Boop FA, Klimo Jr P. Pediatric intracranial gunshot wounds: The Memphis experience. J Neurosurg Pediatr. 2016; 17(5): 595 - 601. https://doi. org/10.3171/2015.7.PEDS15285.

6. Izci Y, Kayali H, Daneyemez M, Koksel T. Comparison of clinical outcomes between anteroposterior and lateral penetrating craniocerebral gunshot wounds. Emerg Med J. 2005; 22(6): 409 - 10. https://doi.org/10.1136/ emj.2004.014704.

7. Ewing-Cobbs L, Thompson NM, Miner ME, Fletcher JM. Gunshot wounds to the brain in children and adolescents: Age and neurobehavioral development. Neurosurgery. 1994; 35(2): 225 - 33; discussion 233. https:// doi.org/10.1127/00006123-199408000-00007.

8. Kaufman HH, Timberlake G, Voelker J, Pait TG. Medical complications of head injury. Med Clin North Am. 1993; 77(1): 43 - 60. https://doi. org/10.1016/s0025-7125(16)30271-1.

9. Tandean S, Risfandi M, Japardi I. Pediatric gunshot penetrating head injury: A case report with 2-year follow-up. Med J Indones. 2017; 26(4): 302 - 6. https://doi.org/10.13181/mji. v26i4.1472.

10. Kazemi H, Hashemi-Fesharaki S, Razaghi S, Najafi M, Kolivand PH, Kovac S, Gorji A. Intractable epilepsy and craniocerebral trauma: Analysis of 163 patients with blunt and penetrating head injuries sustained in war. Injury. 2012; 43(12): 2132 - 5. https://doi. org/10.1016/j.injury.2012.06.007.

11. Alvis-Miranda HR, Rubiano AM, Agrawal A, Rojas A, Moscote-Salazar LR, Satyarthee GD, et 
al. Craniocerebral gunshot injuries; A review of the current literature. Bull Emerg Trauma. 2016; 4(2): $65-74$.

12. Doan N, Nguyen HS, Patel M, Shabani S, Janich K, Montoure A. Management of gunshot wound to the head in pediatric population: Mini-Review. Ann Pediatr Child Health. 2016; 4(3): $1108-9$.

13. Ford EG, Senac Jr MO, McGrath N. It may be more significant than you think: BB air rifle injury to a child's head. Pediatr Emerg Care. 1990; 6(4): 278 - 9. https://doi. org/10.1097/00006565-199012000-00007.

14. Harris W, Luterman A, Curreri PW. BB and pellet guns - toys or deadly weapons? J Trauma. 1983; 23(7): 566 - 9. https://doi. org/10.1097/00005373-198307000-00004.

15. Amirjamshidi A, Abbassioun K, Roosbeh H. Air-gun pellet injuries to the head and neck. Surg Neurol. 1997; 47(4): 331 - 8. https://doi. org/10.1016/s0090-3019(96)00357-6.

16. Nagib MG, Rockswold GL, Sherman RS, Lagaard MW. Civilian gunshot wounds to the brain: Prognosis and management. Neurosurgery. 1986; 18(5): 533 - 7. https://doi. org/10.1227/00006123-198605000-00003.

17. Kennedy F, Gonzalez P, Dang C, Fleming A, Sterling-Scott R. The Glasgow Coma Scale and prognosis in gunshot wounds to the brain. J Trauma. 1993; 35(1): 75 - 7. https://doi. org/10.1097/00005373-199307000-00013.

18. Levy ML, Masri LS, Lavine S, Apuzzo ML. Outcome prediction after penetrating craniocerebral injury in a civilian population: Aggressive surgical management in patients with admission Glasgow Coma Scale scores of 3, 4, or 5. Neurosurgery. 1994; 35(1): 77 - 84; discussion 84 - 5. https://doi. org/10.1227/00006123-199407000-00012.

19. Irfan FB, Hassan RU, Kumar R, Bhutta ZA, Bari E. Craniocerebral gunshot injuries in preschoolers. Childs Nerv Syst. 2010; 26(1): 61 6. https://doi.org/10.1007/s00381-009-0971-y.

20. Siccardi D, Cavaliere R, Pau A, Lubinu F, Turtas $\mathrm{S}$, Viale GL. Penetrating craniocerebral missile injuries in civilians: A retrospective analysis of 314 cases. Surg Neurol. 1991; 35(6): 455 - 60. https://doi.org/10.1016/0090-3019(91)90179-d.

21. Coughlan MD, Fieggen AG, Semple PL, Peter JC. Craniocerebral gunshot injuries in children. Childs Nerv Syst. 2003; 19(5-6): 348 - 52. https://doi.org/10.1007/s00381-003-0736-y.

22. Bandt SK, Greenberg JK, Yarbrough CK, Schechtman KB, Limbrick DD, Leonard JR. Management of pediatric intracranial gunshot wounds: Predictors of favorable clinical outcome and a new proposed treatment paradigm. $J$ Neurosurg Pediatr. 2012; 10(6): 511- 7. https:// doi.org/10.3171/2012.8.PEDS123.

23. Duda T, Sharma A, Ellenbogen Y, Martyniuk A, Kasper E, Engels PT, Sharma S. Outcomes of civilian pediatric craniocerebral gunshot wounds. J Trauma Acute Care Surg. 2020; 89(6): 1239 - 1247. https://doi.org/10.1097/ TA.0000000000002900.

24. Hopkinson DA, Marshall TK. Firearm injuries. Br J Surg. 1967; 54(5): 344 - 53. https://doi.org/ bjs. 1800540507 .

25. Sarnaik AP, Kopec J, Moylan P, Alvarez D, Canady A. Role of aggressive intracranial pressure control in management of pediatric craniocerebral gunshot wounds with unfavorable features. J Trauma. 1989; 29(10): 1434 - 7. https://doi.org/10.1097/00005373198910000-00023.

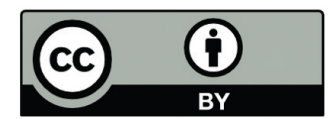

This work is licensed under a Creative Commons Attribution 